\title{
Focussing on Decoding Contractions in English Sentences to Inform ESL Educational Practice
}

\author{
Dennis Michael Bryant (Corresponding author) \\ University of Canberra \\ Kirinari Street, Bruce, Canberra, Australian Capital Territory, Australia
}

Tel: 61-400-499-265Ｅ-mail: DrDennisBryant@gmail.com

Received: November 24, 2019 Accepted: December 16, 2019 Published: December 24, 2019

doi:10.5296/ijch.v6i2.15892 URL: https://doi.org/10.5296/ijch.v6i2.15892

\begin{abstract}
The thesis presented herein is that English is obsessive towards some of its character-set, and this is evident with the grammatical use of letters D, S, M, R, L and V. It is expected that critical investigation of this obsession will inform Educational Practice - especially Teaching and Curricula - and this could enable increased success for ESL student cognizance of grammatical associations, thereby supplanting the need for rote-learning, to some degree. This is not to say that teachers must become concerned necessarily with grammar research at a macro-level - and accordingly this paper concerns itself with informing the readership on micro-level grammar. This goal is to be achieved through a method of providing a suite of examples, and while noting grammatical inter-relationships, also acknowledging that the examples conform to an underlying but seldom (if at all) mentioned theme of operation in English; namely, a penchant for reuse.
\end{abstract}

Keywords: English grammar, ESL curricula, ESL educational practice, SLA

\section{Introduction}

Are today's linguistic descriptions of grammar reliable, and are they complete? This is a timely question about reliability due to the recent but eventful research by Everett (2016, 2005), who claims to have provided credible evidence for the falsification of the widely acclaimed Universal Grammar (UG) premise by Chomsky $(1965,1957)$. With the UG 
premise under threat and representing a potentially imminent fall from grace, why would teachers concerned with curricula and educational practice excellence not be concerned? Staying with a micro-grammar approach, and believing that linguistic definitions of English are incomplete at a morphemic level, this paper shows that linguistic definitional discrepancies have persisted for a considerable time, in fact from the early twentieth century till today. The discrepancies do not revolve around an inability to describe a morpheme as a 'word', which certainly has been done. Rather, there seems to have been a sustained failure to provide explications that clearly go beyond the simplistic. This statement might seem to be a harsh criticism, but Sapir notes that 'the strong craving for a simple formula has been the undoing of linguists' (1921, p. 122). In response to the challenge of clarity, this paper will provide a modest but credible, systematic explication that is intended to inform effectively ESL teaching, curricula-building and educational practice.

\section{Discussion}

Although Wrenn discusses morphology (1949), as did Sapir before him (1921), Wrenn does not employ the term 'morpheme', instead making use of 'word'. Nevertheless, Wrenn does extend the morpheme concept by stating that 'the endings of words may be used to shew (sic) their relationship[s]' (1949, p. 106). This statement obliquely recognises that some words can act in a grammatical capacity rather than in a lexical-only capacity. If there was an elephant in the room that Wrenn was trying to sidestep, that elephant could be surmised to be concerned with word classes. Wrenn hints at this when he decries a lack of mathematical precision in language, which causes a blurring of word classes. In this regard, he espouses the same view held by Sapir that 'our conventional classification of words into parts of speech is only a vague, wavering approximation' (1921, p. 117).

In a text book that was accredited for use in English classes in secondary schools in New South Wales in Australia, Mitchell describes words as having 'grammatical terminations and affixes' (1962, p. 23). However, a definition for grammatical is not given explicitly, but, rather, by illustration through usage. A description, which comes closest to a definition, is the assertion made therein that changes in morpheme shape, through inflection, can result in changed word class membership. To exemplify his position, Mitchell declares that 'the 's shows that nouns are possessive' (p. 23). If the apostrophe-S were to indicate a change in word class, as Mitchell declares, it would be a small, and perhaps even trivial change - from Proper Noun to Possessive Proper Noun (as in, Peter'S); or from Common Noun to Possessive Common Noun (as in, the woman'S).

In a textbook with accreditation equivalent to Mitchell's publication (1962), but sidestepping word classes, Gunn \& Eagleson revert to Latinate descriptions in declaring to their student audience that 'John'S' is 'Genitive (possessive)' (1966, p. 127). In providing this passé definition, it is most difficult to see advantage accruing to students in any of Gunn \& Eagleson's multiple reprints. In fact, Gunn \& Eagleson's regression to Latinate terminology is surprising because the almost total loss of inflections from English over time, as well as the periphrastic nature of English, had long been reported and seemingly accepted (see, Wrenn, 1949), because Greenberg (1973) was soon to release a paper that classified English as an SVO (Subject-Verb-Object) language where positioning was the vital key in sentence 
construction, not case inflections.

At this point in trying to understand the educational service being delivered by linguists, it is difficult to accept what seems to be a fascination with word classes. Specifically, would it not be correct to think that an apostrophe-S functions to convert a word (Proper Noun and Common Noun, alike) into an adjective, as in 'the-average-man-in-the-street's opinion'? In summary, the importance of word-function appears to have been overlooked by linguists, in favour of word class membership status fascination.

In a step away from word classes, Bolinger (1968) proposes a four-way definition of a morpheme. Briefly, there are source morphemes and system morphemes. Bolinger's source morphemes might best be described as lexical words that have meaning, as in 'horse', and the meaning is extensible, as in 'horse-shoe' where another morpheme has been sourced to form a compound. Interestingly, one of Bolinger's examples shows 'push' extending to 'pushy', ( $p$. 59). In this case, it would seem that Bolinger was accepting the case for a phoneme (here, the letter ' $y$ ') to act as a morpheme; that is, recognition that a morpheme can be comprised of a single letter. Perhaps blind to a simple explanation, Bolinger laments that 'the relationship of morphemes to words is therefore the hardest thing in language to analyse' (1968, p. 55).

As a postscript to the above discussion on Bolinger's viewpoints, it is difficult to accept as proven, nor as correct, Bolinger's baleful assertion that English is 'unsystematic... and so burdened with conflicting systems' (p. 56). That comment, as unhelpful as it is, brings to light the reason for this paper; namely, to show that English can be viewed (with some ease) as operating in a systematic and predictable manner, with regard to morphemes. This ease is relatively transparent, but it does become opaque when trying to impose a pre-conceived, alien model onto English.

If there is an improvement in definitions over time, Langacker (1973) certainly reflects that improvement. He excels, perhaps unknowingly, by postulating 'free and bound morphemes' as types (p. 75), and these type-names would seem to better reflect the actual reality experienced in speech. On the debit side of the ledger, it would have been a wonderful opportunity for Langacker to knowingly pose a premise: can a multi-lettered word, such as the free morpheme 'would', also be viewed as functioning in an equivalent grammatical manner, when it is reduced to the single-lettered phoneme (that is, D) and thereby acts as a minimalist-sized morpheme bound to a free morpheme (as in, he'D)? Langacker's (1973) failure to see such a connection might have been caused by reluctance to accept the premise that a phoneme can be assigned (in what might be called English's propensity to reuse elements) to serve as a bound morpheme. In this reluctance, Langacker was not unlike others, such as Bolinger. Perhaps distressed by not being able to see this connection, but not intending to demean his contribution, Langacker's discussion is nevertheless ironic, because juxtaposed hard up against his type definitions, he concludes that his own 'distinctions [read 'types'] are rather superficial' (1973, p. 76).

Although linguists have continued producing commentaries on grammar (see, Torres-Gouzerh (2019); Swick (2009); Van Valin (1997); Borsley (1991); Matthews (1991), as examples), the start of the twenty-first century delivered linguists a rude shock. The long-celebrated but infrequently-challenged UG premise (Chomsky, 1965) was claimed to be falsified, not once but on two different criteria, in fresh research by Everett $(2016,2005)$. The 
clear implication is that those curricula which have been built on the UG premise have not been delivering excellence to students; that is, a return to basics may well be needed, and such action has been suggested to be justified on syntactical grounds (Bryant, 2019a) and morphemic grounds (Bryant, 2019b). Another author who would agree is Truss (1993), and while she is addressing only a part of the wider problem, her commentary on apostrophe usage does give inspiration. She says 'Too many jobs have been heaped on this tiny mark...[and]...isn't it time to recognize that the apostrophe needs our help?' (1993, p. 36-37).

\section{Methodology}

This paper proceeds by presenting a modest range of English exemplar sentences. Each sentence includes at least one contraction example. The exemplar sentences are accompanied by grammatic commentary, as well as providing a limited range of comments for teacher use which, if passed on, may help students formulate a fresh, mnemonic appreciation for each of the abbreviated contractions. Discussion is organised into sections, which are arranged by the letter which appears in the contraction (such an example is apostrophe-D). Not all sections are of equal size, since some letters are involved in more contractions than other letters. Such is the case with apostrophe-D contractions having more definitions than apostrophe-M contraction.

A fresh approach has been taken for two cogent reasons, both of which concern the aspect of student visibility. While extant writings exude goodwill towards ESL student acquisition success (see for example, Christison (2002), Dornyei (2001), Cohen (1998)), this paper's approach presumes to address visibility as students encounter it. In fact, and taking apostrophe-D as an example, would it not be reasonable to suggest that students encounter apostrophe-D as an un-decoded signal that is camouflaged in plain sight? It seems fair to use the term 'camouflaged', because ESL speakers do not see apostrophe-D as a code of simplicity, as a red or green or amber light would be, making its interpretation prone to error.

The second reason, for this fresh approach, concerns autonomy. This paper agrees with Benson (2001) that the availability of opportunities to exercise control over learning can accelerate student learning, and this paper's approach is possibly more complete, and therefore more congruous to success than were earlier published attempts. Nevertheless, this paper's primary concern rests with explication, and not per se with delving into learning autonomy.

\section{Findings}

\subsection{Defining a Morpheme}

Recapping, it would not be exaggeration to feel disappointed at not finding convincing instructional illustrations on morphemes; but more so, in finding a lack of conceptualization clarity by linguists. In spite of this shortcoming, a definition of morpheme is not beyond the possible. When not a full word, a morpheme is one or sometimes two lexical letters (such as $\mathrm{D}$; Ve) that are reused to create not a new member of the lexicon, but rather to participate in league with an apostrophe as part of a contraction which serves grammatical convenience (as in as ' $\mathrm{D}$; ' $\mathrm{Ve}$ ). The full contraction is completed by suffixing the apostrophe-cum-morpheme cluster to a nominal (as in, he'D; they'Ve). Restated in Greenbergian terms (1973), one or 
two elements of the adjacent Verb zone can be seconded into the Subject zone, liaising closely with a nominal.

\subsection{Apostrophe-D Contractions}

This section provides examples and explanations of the commonly used convenience D contraction, which represents three auxiliary verbs; these being 'woulD' as well as 'haD' and also 'diD'.

\subsubsection{Grammatical-D of ‘woulD’ Expressing Irrealis Action}

Speakers hypothesize frequently on what actions could happen, in a past, present or at a future time. English uses an auxiliary modal verb to express hypothesized ('irrealis', 'unreal') action. While most free-form modals do not participate in grammatical contraction, modal 'would' is an exception.

$I^{, w} D \underline{\text { allow }}$ my dog off his lead because he ${ }^{\text {,w } D}$ heed my directives.

The example above is a statement about habitual action in which grammatical-D is presented in italicised uppercase to highlight its significance as a contraction indicating irrealis action, while lexical-D is presented in lowercase only. Apart from differentiating the grammatical usage from lexical usage of $\mathrm{D}$, the example illustrates a degree of complexity that ESL speakers must master. With regard to speech, by contrast to encountering the written word, an apostrophe is not available visually to an ESL speaker, but its presence is still detectable. This feature is discussed by Bolinger as the possibility or otherwise of vocalized hesitation insertions (1968, p. 52).

As a possible suggestion to educational staff as regards contraction teaching, a superscript mnemonic indicating the first letter of 'would' has been inserted inside the contraction. Although the insertion of a superscript for mnemonic purposes can be argued as unnecessary interference because there is no such superscript in reality, it is a reasonable point to make that suggesting a mnemonic to possibly enhance second language acquisition is also reasonable because a teacher will dispose or employ the suggestion, as needed.

As a further point on educational mnemonics, the underlining of the verbs is meant to remind students that modal verbs are followed by present tense verbs or the present tense form of auxiliary verb 'have'. As an additional mnemonic, but on this occasion reflecting placement, it would be noted by students that the 'would' contraction happens at a point which links the subject zone to the verbal zone.

\subsubsection{Grammatical-D of 'diD' Exposing an Underlying Form}

The second grammatical convenience role undertaken by D, and of concern to ESL speakers, is 'diD'.

\section{You found my watch! Great! Where ${ }^{\text {d } D}$ you find it?}

The two-part example above is perhaps more subtle than previous example sentences. This is because the underlying free morpheme 'did' was not produced to accompany 'found' in the leading utterance, which could have been realised as 'did find'. In fact, if 'did' had been produced, it would have been a simple algorithm to generate the 'Where' $D$ ' question. 
However, a touch of stress was not required, and 'did' was therefore not evident in the first half of the example. This lack of sentinel 'did' means that an ESL speaker has to pursue a more complex algorithm, that being: to remember to insert 'did'; then tailor it to become a contraction of grammatical convenience; and finally to attach the contraction to the nominal 'at what place', which itself is abbreviated to 'where'.

In addition to the superscript insertion, but in terms of building a mnemonic distinguishing the 'did' and 'would' contractions, it would be noted by students that 'did' was promoted from its verbal zone to a position preceding the subject, to form a question. Additionally, 'where' has been inserted prior to 'did', in order to seek information beyond a simple 'yes' or 'no' answer to the question. The 'did' contraction then links the question-forming words, both of which precede the subject zone.

You found my watch! Great! Where * you found it?

If an ESL speaker fails to remember that 'did' insertion is required, they are likely to (and actually do) produce the ungrammatical example shown above. What is worse, those speakers may become locked into this ungrammatical usage, which is a situation that Pienemann refers to as plateauing (1998).

In defence of the plight of students, it may be the case that speakers are distracted from remembering to engage do-insertion due to the existence of an ambiguous definition of WH-words. In a number of textbooks, WH-words are described to students as question words. This definition is unfortunate because it suggests, awkwardly, that the presence of a WH-word primarily creates a question, but to students this suggestion can function as a clear, but unfortunate, invitation to dismiss the prime role of auxiliaries in question formation.

\subsubsection{Grammatical-D of 'haD’ Expressing Past Completed Action}

The third grammatical convenience role undertaken by $\mathrm{D}$, and of equal concern to ESL speaker success, is 'haD'.

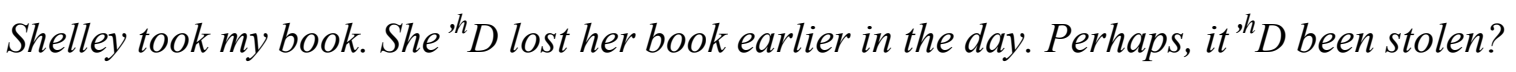
In the example above, $\mathrm{D}$ is used in a contraction that concerns the past relevance of time. The next point to note is the use of $\mathrm{D}$, for a third time, in a contraction, but portraying a clearly different circumstance. Incidentally, the example also shows an apostrophe-D contraction within a passive voice construction. In might seem to be hyperbole, but English appears to be unstoppable in its determination to pursue a policy of reuse. While it would be untimely to relate this determination to students, and of course acknowledging that English does not set out to confuse, the hidden benefit which should eventually accrue to speakers from this determination is an elegant economy of expression.

In terms of building a mnemonic distinguishing the 'had' and 'would' contractions, in which contraction happens to both at a position linking the subject zone to the verbal zone, it would be noted by students that 'had' precedes a past tense verb, whereas 'would' (as does it's contracted form of course), precedes a present tense verb.

\subsection{Apostrophe-S Contractions}

The following section provides examples and explanations of three commonly used ' $\mathrm{S}$ grammatical convenience contractions, which represent the auxiliary verb 'haS' as well as 
'iS', but also includes a third option which is polemic.

\subsubsection{Grammatical-S of 'haS' Expressing a Temporal Inference}

The first grammatical convenience role undertaken by S, and of interest to ESL speaker success, is 'haS'.

\section{If she ${ }^{\text {,h }} \underline{\text { taken }}$ the highway, she'll be late. There ${ }^{\text {,h }}$ been an accident.}

In the example above, $\mathrm{S}$ is used in a contraction that carries a time inference, as does its alternate form, 'have', discussed in a later section. Because the definition of a contraction specifies appendage to a nominal, but 'There' does not appear at first blush to be a nominal, a momentary detour to comment must be taken. There are two indications that support 'There' as a nominal. Under the SVO premise (Greenberg, 1973), 'There' sits alone in the Subject zone and abuts but is separated from the Verb zone. Ergo, this marks 'There' as a nominal. Secondly, and taking a semantic approach, 'There' appears to carry a meaning of a nominal phrase, namely, 'At that place'.

As a remark on educational mnemonics, the underlining of the verbs is meant to remind students that the 'has' auxiliary verb contraction is followed by past tense verb. An additional mnemonic, but on this occasion reflecting placement, it would be noted by students that the 'has' contraction happens at a point which links the subject zone to the verbal zone.

\subsubsection{Grammatical-S of 'iS' Expressing an Ongoing Feature}

The next convenience role undertaken by $\mathrm{S}$, and of equal interest to ESL speaker success, derives from 'iS'.

\section{$H{ }^{{ }^{i} S}$ working for my brother but, sadly, he ${ }^{i}$ S sick. My brother ${ }^{i} S$ sick too.}

Once again, English makes reuse of the lexical letter $\mathrm{S}$ in a contraction, but this time its employment derives from a different free-form ('iS', rather than the previous example, 'haS') giving it a new role. As a remark on educational mnemonics, it would be noted by students that the exemplar sentences show 'iS' is followed by an adjective; not by a past tense verb, as was the case for the previous 'haS' contraction example.

By way of explanation, 'working' may seem to be a verb featuring an '-ing' continuity inflection; yet, it may be interpreted here as representing being in a state of working, just as the 'sick' adjective represents being in a state of sickness, and therefore can be conceived of as an adjective. The concept of word class mobility would seem to support this interpretation. As an additional mnemonic for 'iS' but based on placement, it would be noted by students that the 'iS' contraction happens at a point which links the subject zone to the verbal zone.

As an aside to contractions, there is a relationship between these two grammatical-S conveniences -based on usage- because both are used to support a singular third-person entity (as in examples such as, 'he', 'brother', 'my neighbourhood', and 'a Tax Authority').

\subsubsection{Grammatical-S as an Indicator of So-Called 'Possessive Ownership'}

The example below features a case that emulates contraction convincingly on some, but not all points. Nevertheless, its grammatical convenience role in representing ownership will be of interest to ESL speakers. 
Diane'S, tall, redheaded, friend visited yesterday.

For example, as regards differences, there is no immediately obvious underlying reflection of a free-form for $\mathrm{S}$ here. In the absence of a similar-looking morpheme, there is 'of', which is dissimilar in form, but congruous in terms of functionality in cases like 'The Queen of England'. Was the underlying free-form lost in historical times? Writing on the topic of Old English, Mitchell notes that possessive is indicated by 'the [genitive case] ending -es' (1995, p. 35). This same ending was still in use in Chaucer's dialect of fourteenth century Middle English to indicate genitive (and plural) forms. Cook notes that 'This final -es is usually pronounced as a separate syllable' (Cook, 1961, p. xxiii), implying it was strongly voiced, as it is today. By Shakespeare's time, this ending had been reduced, due to the loss of its leading 'e,' to simply an apostrophe-S. This adapted usage is seen in the title of one of Shakespeare's plays - such as, Love's Labor's Lost - and within the text of his plays (1962, 1965).

Leaving aside the historical developments, it is time to return to the question of whether this usage of apostrophe-S can be viewed as constituting a contraction, in its so-called possessive role. In its favour is the fact that $\mathrm{S}$ is appended also to a nominal. However, against its inclusion into the contraction category, the modified nominal does not function as the main nominal in a subject zone. In reality, it appears that Diane's has shed its earlier nominal status to function as an adjective alongside the other two adjectives shown in the example sentence. This change is unsurprising in a language that favours word class mobility. While the definition of contraction, given earlier, might have inferred but did not explicitly state that a nominal must continue to function as a nominal post-contraction, it is a reasonable stance to not discount the case for calling 'Diane' $S$ ' a full contraction. For this reason and in spite of its historical genesis, it has been included in this section alongside other grammatical convenience $\mathrm{S}$ contractions.

As a remark on educational mnemonics, but on this occasion reflecting placement, it would be noted by students that this contraction happens at a point in the subject or object zones, coexisting with other adjectives, if others are used, in a pre-nominal position.

\subsection{Apostrophe-M and Re contractions}

The following section provides an example and explanation of the commonly used first person singular convenience $\mathrm{M}$ contraction.

\subsubsection{Grammatical-M of 'aM' Expressing Continuing Presence}

\section{I'M happy to know that My invitation was sent to Me yesterday. You'Re not jealous?}

In the example above, $M$ is used in a convenience contraction that appends itself, as is the custom, to a nominal. It carries a sense of continuing presence. The lexically-used $\mathrm{M}$ is presented also in italicised uppercase merely to remind readers of the difference between lexical form and the grammatical contracted form of the same letter.

\subsubsection{Grammatical-Re of 'aRe' Expressing Continuing Presence}

You'Re not jealous? They'Re not!

Contractions are shown above in second and third person plural stative sentences. 


\subsection{Apostrophe-LL Contraction}

This section provides an example as well as a brief explanation of the commonly used grammatical convenience LL contraction, representing an imagined future action.

\subsubsection{Grammatical-LL of 'wiLL' Expressing Irrealis Action}

My friend'LL drive you home safely. She'LL be here soon.

In the example above, LL is a modal auxiliary which is used in a grammatical contraction that appends itself, as is the usual custom, to a nominal in the noun zone. It carries a sense of action that is likely to happen in the future. Unlike previous examples where the underlying auxiliary reduces to a single letter, in this instance the reduced form is deemed to be two letters. However, this conformity to spelling norms does not seem to challenge the definition of a contraction.

\subsection{Apostrophe-Ve Contraction}

This section provides examples and explanations of the commonly used grammatical convenience 'Ve contraction. There is an upswing in importance that surrounds 'haVe' (as well as its reduced convenience 'Ve form) because its usage opens up access to strong verbs acting in past tense. This statement about access also is true for the third person singular form 'haS'.

\subsubsection{Grammatical-Ve of 'haVe' Expressing a Temporal Inference}

I'Ve taken your keys. Hopefully, I'll be back soon.

In the example above, the free-form 'haVe' morphs to participate in a grammatical contraction, appearing as nominally-appended 'Ve. Such usage suggests an ongoing relevance of the present action. That is, in the example above, the speaker can be seen to be drawing the listener's attention to the absence of keys, and an inferred inability to use a car, at least for the moment. This is a second example in which the underlying form reduced not to a single, but rather two letters. But two letters is not a challenge to the definition of a contraction because English uses ' $\mathrm{e}$ ' as a trailing letter, usually to indicate that the preceding vowel is long. For example, in the utterance 'Do you have a hat that you hate?' the final vowel of 'hate' is a guide to lengthening the prior vowel's pronunciation, but is not pronounced itself.

\subsection{Combining Contractions}

Two further instances of contraction are discussed in this section, the first of which is shown in the example, below.

4.7.1 Grammatical-D of Irrealis 'woulD' Contracting with Grammatical-Ve of Temporal Inference 'haVe'

Had I known my dog was going to be obedient, I'D'Ve let him off the lead earlier.

Each of these contractions has been treated in earlier discussion, and there is little to add, except to say that it is a powerful double contraction, suggesting a relentless flexibility of English. A description of 'powerful' is justifiable because it blends into the main verb, in 
quick succession, an irrealis and a temporal relevance. Mastery of this subtlety is vital for ESL student progression.

4.7.2 A Full Modal Contracting with 'Not', Including Grammatical-Ve of Temporal Inference 'haVe'

The final double contraction including, at last, negatives is shown below. Additionally, it features an emancipating twist.

She mightN'T'Ve changed. No, she couldN'T'Ve changed. She oughtN'T'Ve changed, anyway.

This is a situation in which participation in a double contraction is possible for all free-form single-word modals (such as 'might'). Speaking of doubles but moving to a slightly different plane, if 'ought to' is considered to be a two-word modal, then contraction is not entirely limited to single-word modals. However, since 'to' was dropped from the 'ought to' during the contraction process, it suggests a pragmatic ceiling of two contracting partners (aside from the apostrophe) is preferred, which is a limit seen in earlier examples. Yet, this preference is not a hard and fast rule, as there may be dialects of English which readily accept a variation like 'She ought $N$ 'T to'Ve borrowed my car', at least in speech.

\section{Limitation}

There is no treatment of $\mathrm{S}$ as a suffix marker denoting nominal plurality; nor is there treatment of $\mathrm{D}$ (and not forgetting $\mathrm{N}$ ) both of which can act as suffix markers denoting verbal past tense. Although these suffixes do serve grammatical convenience, they are not deemed to be contractions because they require no apostrophe, and do not change zone membership. For these reasons, they are deemed to function as inflections. However, by limiting discussions in this paper to contractions, there is no inference intended to suggest that the reuse of S and D in grammatical inflections may not challenge some ESL learners as they encounter grammatical contractions.

\section{Conclusion}

This paper took the stance that a critical treatment of grammatical convenience in English, as is evident in morphemic contractions, can be most helpful to ESL speakers if that treatment is organised systematically, and is thorough. This claim is especially true as regards the small but frequently-used set of morphemes that are reducible (generally) to a single letter, and find friendship in an attachment to a different word class.

The difficulty in presenting a critical analysis is not governed here by the number of convenience forms that need to be considered - it is actually modest in size. The difficulty exists in that English believes firmly in the reuse of many grammatical features, and in this regard, the feature of grammatical convenience is not an exception. In fact, the multiple reuse of a just a few of its characters may give rise to a conclusion that English is obsessive towards some of its character-set. Adding to the of challenge of ESL learning is the dilemma that a single character (such as D) must be decoded for its exact meaning, according not to lexical context alone, but necessitating also a consideration of grammatical coherence.

Hopefully, time will show that this paper has contributed to informing communicators who 
are concerned with teaching, curricula and educational practice excellence. If better informed outcomes are achieved in practice, it will mean that this paper has succeeded in bringing together a creative discussion from which historically disparate, incomplete and outdated grammatical commentary has been removed.

\section{References}

Benson, P. (2001). Teaching and researching autonomy in language learning. New York: Longman.

Bolinger, D. (1968). Aspects of Language. New York: Harcourt, Brace \& World, Inc.

Borsley, R. (1991). Syntactic Theory. London: Edward Arnold.

Bryant, D. (2019a). Focussing on Promotion in English Sentences to Inform ESL Educational Practice. Language, Literature and Culture, 2(3), 108-113. [Online] Available: http://www.aascit.org/journal/archive?journalId=932

Bryant, D. (2019b). Focussing on Building up ESL Perception of Verb Slot Complexity to inform Educational Practice. Language, Literature and Culture, 2(3), 133-138. [Online] Available: http://www.aascit.org/journal/archive?journalId=932

Chomsky, N. (1957). Syntactic structures. Mouton: The Hague.

Chomsky, N. (1965). Aspects of the theory of syntax. New York: Harper \& Row. https://doi.org/10.21236/AD0616323

Christison, M. A. (2002). Multiple intelligences and language learning: A guidebook of theory, activities, inventories, and resources. Burlingame, CA: Alta Book Center.

Cohen, A. D. (1998). Strategies in learning and using a second language. New York: Longman.

Cook, D. (1961). The Canterbury Tales of Geoffrey Chaucer. New York: Anchor Books.

Dornyei, Z. (2001). Teaching and researching motivation. New York: Longman. https://doi.org/10.1075/hop.5.mot1

Everett, D. L. (2005). Cultural Constraints on Grammar and Cognition in Pirahã. Current Anthropology, 46(4), 621-646. https://doi.org/10.1086/431525

Everett, D. L. (2016). An Evaluation of Universal Grammar and the Phonological Mind. Frontiers in Psychology, 7(15). https://doi.org/10.3389/fpsyg.2016.00015

Greenberg, J. H. (1973). Some Universals of Grammar with Particular Reference to the Order of Meaningful Elements. In J. H. Greenberg (Ed.), Universals of Language (pp. 73-113). London: MIT Press.

Gunn, J., \& Eagleson, R. (1966). English Language for Senior Students: Survey of Language (Vol. II): Angus and Robertson.

Langacker, R. W. (1973). Language and its Structure: some fundamental linguistic concepts 
(2nd ed.). New York: Harcourt Brace Jovanovic, Inc.

Matthews, P. (1991). Morphology (2nd ed.). Cambridge: Cambridge University Press. https://doi.org/10.1017/CBO9781139166485

Mitchell, A. G. (1962). The Use of English. Sydney: Angus \& Robertson.

Mitchell, B. (1995). An Invitation to Old English and Anglo-Saxon England. Oxford: Blackwell Publishers Ltd.

Pienemann, M. (1998). Language processing and second language development: Processability Thoery. Amsterdam: Benjamins. https://doi.org/10.1075/sibil.15

Sapir, E. (1921). Language: An Introduction to the Study of Speech. New York: Harcourt, Brace \& World, Inc.

Shakespeare, W. (1962). The Tempest. London: Longmans, Green and Co Ltd.

Shakespeare, W. (1965). The Merchant of Venice. New York: The New American Library.

Swick, E. (2009). Verbs and Essentials of Grammar for ESL Learners. New York: McGraw-Hill.

Torres-Gouzerh, R. (2019). Practice Makes Perfect: Intermediate English Grammar (3rd ed.). New York: McGraw-Hill Education.

Truss, L. (2003). Eats, Shoots \& Leaves: The Zero Tolerance Approach to Punctuation. London: Profile Books.

Van Valin, R., \& Lapolla, R. (1997). Syntax: Structure, Meaning and Function. Cambridge: Cambridge University Press. https://doi.org/10.1017/CBO9781139166799

Wrenn, C. L. (1949). The English Language. London: Methuen \& Co. Ltd.

\section{Copyright Disclaimer}

Copyright reserved by the author(s).

This article is an open-access article distributed under the terms and conditions of the Creative Commons Attribution license (http://creativecommons.org/licenses/by/3.0/). 